\title{
The impact of a tidal barrage on coastal flooding due to storm surge in the Severn Estuary
}

\author{
Qian $\mathrm{Ma}^{1}$ (1) $\cdot$ Tulio Marcondes Moreira ${ }^{1,2} \cdot$ Thomas A. A. Adcock $^{1}$ (1)
}

Received: 17 April 2019 / Accepted: 10 August 2019 / Published online: 24 August 2019

(c) The Author(s) 2019

\begin{abstract}
The proposed Severn Barrage is a controversial but widely discussed proposal to generate clean and renewable energy. A key concern with this technology is that such structures may cause other environmental problems. However, such structures might also have beneficial environmental effects in some areas, such as mitigating coastal flooding from storm surges. In this paper, we model the hydrodynamics of the Severn Barrage and surrounding area using a depth-averaged numerical model. We simulate a storm surge event based on realistic meteorological conditions coinciding with a spring tide. We find that to the east of the barrage the peak water level is significantly reduced by the barrage. To the west of the barrage, on the ocean side, the presence of the barrage leads to a small increase in the water levels during a surge event despite the reduction in the tidal amplitude. We examine different operational strategies for the barrage during a storm event- these make a small but perhaps significant difference. Overall, a barrage can help to mitigate the impact of storm surges on coastal flooding.
\end{abstract}

Keywords Ocean renewable energy $\cdot$ Storm surge $\cdot$ Severn Barrage

\section{Introduction}

There have been many proposals for a Severn Barrage to generate energy from the tide. The Severn Estuary has one of the largest tidal ranges in the world and is surrounded by centres of population and industry, making it a promising site for tidal range technology. The first detailed proposals began with the seminal technical study into the feasibility of the project led by Bondi (1981) and developed further by the Severn Tidal Power Group (STPG) (STPG 1989). More recently, the Department of Energy and Climate Change studies (DECC 2008), which was based on the original Bondi and STPG proposal, and the Hendry Report (Hendry 2016) have provided an up-to-date summary of the proposed project. Estimates of the power that the scheme might generate are given in Table 1. Recent academic research include analytical studies such as Rainey (2009), Draper (2013) and numerical

Qian Ma

qian.ma@eng.ox.ac.uk

1 Department of Engineering Science, University of Oxford, Oxford, UK

2 Department of Computer Science, Federal University of Minas Gerais (UFMG), Belo Horizonte, Brazil modelling including Falconer et al. (2009), Ahmadian et al. (2010) and Xia et al. (2010).

Any tidal barrage structure will have a major environmental impact and this needs to be understood before installation Neill et al. (2018). One important impact will be on storm surges (changes in water level driven by atmospheric forcing). It has been suggested that a barrage may provide protection against coastal flooding from storm surge. Indeed, similar structures are used explicitly for this purpose, such as with the Thames Barrage and the Delta Works. It is obvious that the physical barrage can be used to prevent the surge travelling upstream of the barrage if appropriately operated. However, negative consequences might be expected on the ocean side of the barrage. Understanding how storm surges would interact with the proposed Severn Barrage is the focus of this paper.

The high tidal range of the Bristol Channel means that coastal flooding from storm surge is relatively rare. If a storm surge event occurs other than during spring tides, the increase in water level will not be sufficient to cause flooding. Highest tidal water levels occur around the equinoxes whereas the worst storm surges will be in the middle of winter (see Gao 2017) again reducing the impact of surges on coastal flooding. However, on rare occasions, a significant storm surge will coincide with a spring tide and this has the potential 
Table 1 Estimates of the power generated by a Severn Barrage

\begin{tabular}{lll}
\hline Source & $\begin{array}{l}\text { Annual } \\
\text { energy output } \\
\text { (TWh) }\end{array}$ & $\begin{array}{l}\text { Total capacity } \\
\text { (MW) }\end{array}$ \\
\hline Bondi Committee (1981) & 12.9 & 7200 \\
STPG (1989) & 17 & 8640 \\
DECC (2008) & 16.8 & 8640 \\
Xia et al. (2010) & 17.7 & 8640 \\
Hafren Power (2013) & 16.5 & 6500 \\
\hline
\end{tabular}

for very major consequences given the large amount of lowlying land surrounding the estuary and the high population. In 1607, a major flooding event due to storm surge occurred in the area (Horsburgh and Horritt 2006) causing significant damage to a large area around the estuary. The impact of such an event today would run into many billions (Horsburgh and Horritt 2006; RMS 2007).

To our knowledge, no detailed study has been carried out into the interaction of storm surge with the Severn Barrage or with any other tidal energy barrage. Lyddon et al. (2015) studied the impact of storm surge interaction with tidal lagoons. The present authors have also considered the interaction of storm surge with the Swansea Lagoon (Ma et al. 2019).

The approach we have taken is to create a depth-averaged numerical model of the region with the Severn Barrage included. The model is validated both for tidal elevation and for hindcast storm surge events. To create a potential coastal flooding event, we combine a real atmospheric event with a high-tide event. This is then used to investigate the interaction of storm surge with the Severn Barrage for different operational strategies. We separately examine the effect on tidal hydrodynamics and storm surge before combining these to analyse the change in overall water level.

\section{Numerical model}

This paper models the tidal and storm surge hydrodynamics using the shallow water equations with the standard source terms for bed friction, Coriolis effects, and an 'eddy viscosity' term [see, for instance, Pugh (1996)]. The shallow water equations are solved using the discontinuous Galerkin model DG-SWEM (based on the well-known ADCIRC model) (Kubatko et al. 2006; Westerink et al. 2008; Dawson et al. 2011) with unstructured triangular mesh. Figure 1 depicts the domain of the model, which is based on that of Serhadlıoğlu et al. (2013) with resolution improvement in some areas. A formal convergence test (looking at both $\mathrm{h}$ and $\mathrm{p}$ convergence) has been conducted by Serhadlıoğlu on the original model (Serhadlığlu 2014). Checks were carried out when editing this mesh around the barrage to check the results were

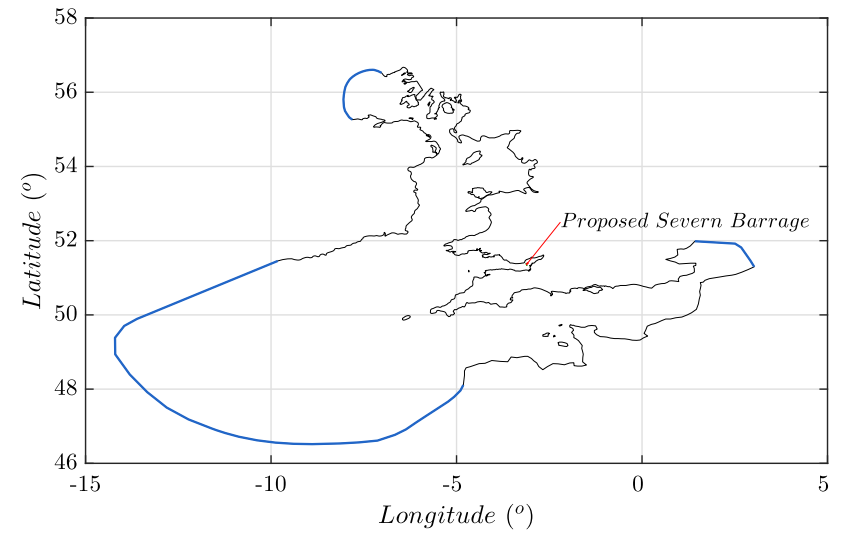

Fig. 1 Model computational details of the model domain, blue lines show the ocean boundaries

mesh independent. The model domain includes the Irish Sea, Celtic Sea, English Channel and Bristol Channel [the latter from the model of Adcock and Draper (2014)], and is divided into 51,458 nodes and 98,278 elements of unstructured triangular cells for the mesh where there is no tidal lagoon (including a barrage structure requires minor remeshing). Details about the mesh around the turbines can be found in Schnabl et al. (2019). The model is forced with the three principle semi-diurnal tidal constituents $\left(M_{2}, S_{2}\right.$ and $\left.N_{2}\right)$.

Detailed validation of the tidal hydrodynamics of this model has been presented elsewhere Serhadlığlu (2014), Gao (2017) and with a focus on the Bristol Channel in Ma et al. (2019). As such we do not repeat this validation study in detail in the present paper. Without the barrage present, the model shows good agreement with water level measurements in the Bristol Channel and, perhaps surprisingly, acceptable agreement with the limited measurements of current in the region.

\subsection{Representation of storm surges in the model}

We force the numerical model using wind and pressure data from hindcasts. For simplicity, we neglect the forcing from radiation stress from the waves as this is expected to be relatively small in the region and it is difficult to model this around a barrage. The atmospheric surface pressure and 10-m wind velocity data have been taken from the ERA5 reanalysis data sourced from the European Centre for Medium-Range Weather Forecasts (ECMWF) (Dee et al. 2011). Another two datasets with different spatial and temporal resolutions, the ERA-Interim and the MÉRA dataset Met Éireann (2018), have been examined as well for storm surge simulation in the Bristol Channel. However, the agreement between the surges predicted when using these alternative meteorological models and measured data are not as good as with the ERA5 model. 


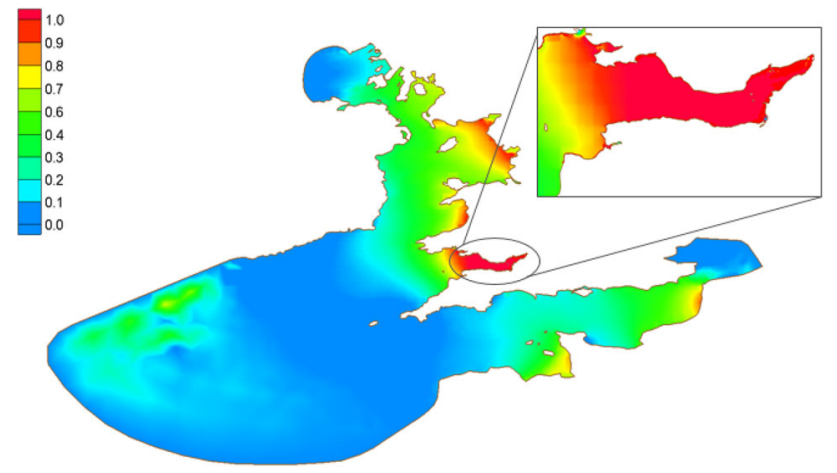

Fig. 2 Simulation results of the surge residual during the storm surge events of 2000 for whole domain predicted and shown by DG-SWEM

It is straightforward to apply pressure data to the model. However, the wind speed is related to the shear stress by a drag coefficient, $C_{d}$ [see discussion in Bryant and Akbar (2016)]. A detailed discussion calibration of this parameter is given in Ma et al. (2019). For the present work, we use the value given by $\mathrm{Wu}(1969)$.

\subsection{Validation of storm surge modelling}

We validate the meteorological forcing in our model by hindcasting storms and comparing the water levels predicted to field data. Two storm surge events are considered: the event on the 13 December 2000 with available field measurement data at the Avonmouth station $\left(51.51^{\circ} \mathrm{N} 2.71^{\circ} \mathrm{W}\right)$ and the event on the 12 February 2014 at the Ilfracombe station $\left(51.21^{\circ} \mathrm{N} 4.11^{\circ} \mathrm{W}\right)$.

During the storm surge event in the year 2000, the observed surge level at Avonmouth was greater than $2 \mathrm{~m}$. Figure 2 displays the modelled surge pattern and Fig. 3 compares the model residual predictions with field measurements. The comparisons indicate that the model captures the surge (residual) peak time while the amount of the surge is underestimated by $0.84 \mathrm{~m}$. For other relatively large surges within this period, such as the event at 8.1 into the simulation, the model gives a surge peak of $1.67 \mathrm{~m}$ compared with the measured $1.78 \mathrm{~m}$.

More recently, there was another significant surge event with $1.5 \mathrm{~m}$ residual at Ilfracombe in 2014. Figure 4 compares model and measurements for this event. Good agreement is observed for the peak water level and its timing although for other events around this period there is a significant discrepancy.

Whilst there are discrepancies between measurements and model predictions in these two surge events, we consider these results acceptable for the surge studies. There are multiple reasons for the discrepancies between model and measurement. In our view, the key reason for the discrepancy is likely to be inaccuracy in the hindcast winds and pres-
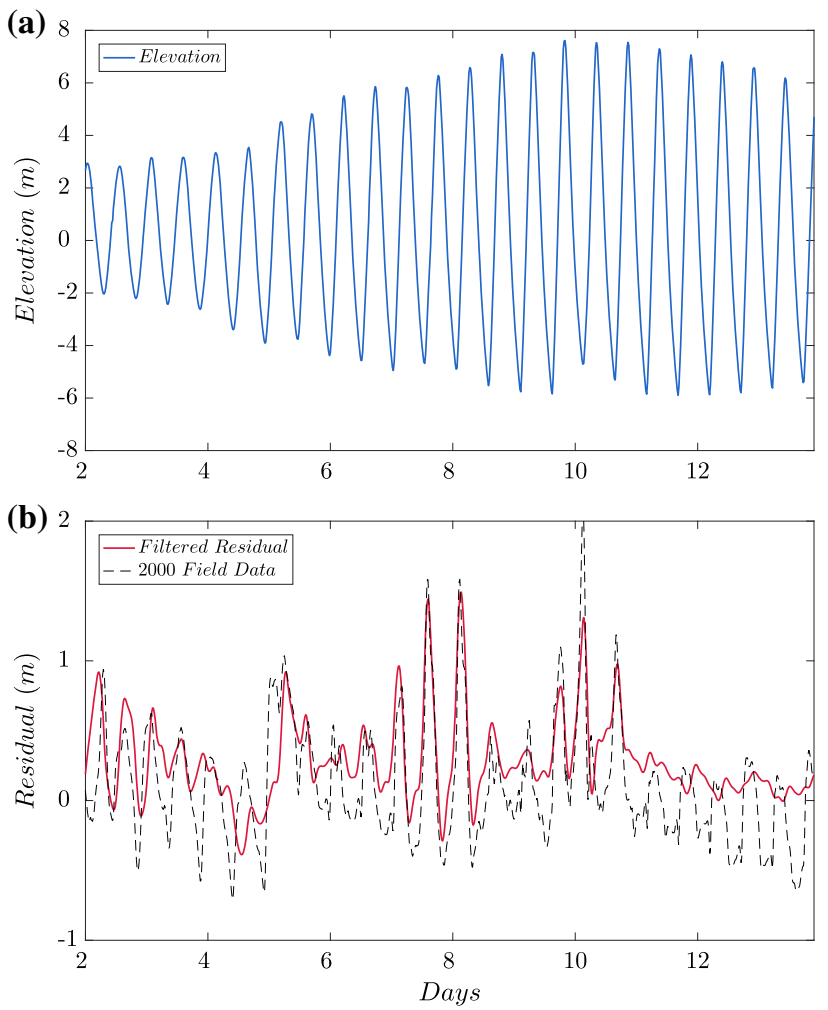

Fig. 3 Simulation results of storm surge events of 2000 at Avonmouth predicted by DG-SWEM and compared with field measurements: a water level (top); b residual level (bottom)

sures which are a crucial input to this model. This limitation was discussed for the region by Proctor and Flather (1989). Discrepancy will also be due to the depth averaged assumption, the application of a single bed friction value, neglecting wave setup, not accounting for bathymetric changes between events, not accounting for river discharges, etc.

In this study, we wish to explore the impact of a major flooding event in the Bristol Channel. Since there has not been a major event in the period for which we have data, we have decided to create a synthetic event. The simulated scenario combines the meteorological conditions of the 2000 surge event with the tides at the peak of the springs. In practice, this simply involves a small shift in the timing of either the meteorological or tidal records. The meteorological conditions of this scenario obviously vary over the domain but in the channel itself during the surge event the wind was $\sim 20 \mathrm{~ms}^{-1}$ from southsouthwest and the pressure was around $99.5 \mathrm{kPa}$. Our synthetic storm has a maximum water elevation at the Severn Barrage site of $7.23 \mathrm{~m}$ relative to mean water level (without barrage implemented). The joint probability of tide and surge is a complex topic but qualitatively we would estimate this to be approximately a 1 -in-100-year water level event. 

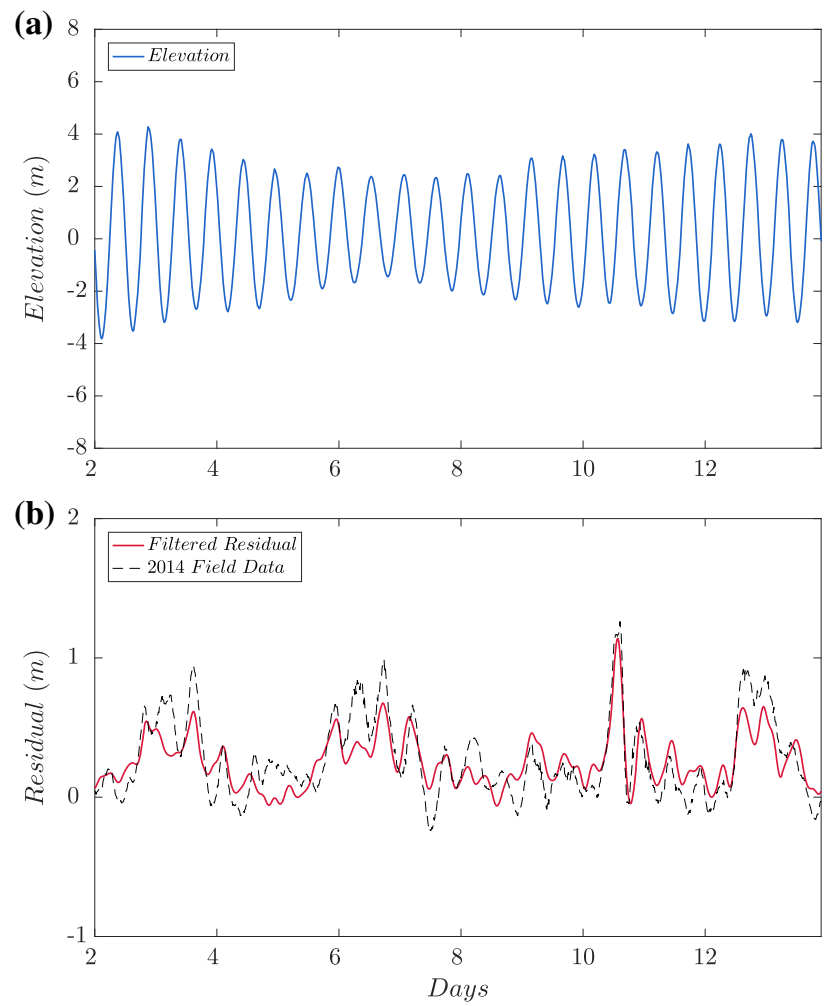

Fig. 4 Simulation results of storm surge events of 2014 at Ilfracombe predicted by DG-SWEM and compared with field measurements: a water level (top); b residual level (bottom)

\subsection{Representation of the barrage in the model (Severn Barrage proposal)}

To include the effects of hydraulic structures (sluices and turbines) in the tidal barrage, this paper utilises a barrage boundary incorporated in DG-SWEM and described and verified in detail in Schnabl et al. (2019). The barrage sub-grid scale model was developed based on a culvert model already present in DG-SWEM (Westerink et al. 2001; Dawson et al. 2011) that adds an internal barrier to the finite element mesh. The internal barrier acts as a reflective boundary throughout its length, except at the node pairs where hydraulic structures are simulated (Fig. 5). The flow through these node pairs is calculated as a function of the water head developed between "front" and "back" sides. The flow during the sluicing phase is modelled using the orifice equation with $C_{d}=1$ (Prandle 1984; Baker 1991), which relates head difference to the flow through the boundary as seen in Eq. (1). The flow through the turbines is modelled using characteristics for a low head bulb turbine following Aggidis and Feather (2012) and Petley and Aggidis (2016).

$$
Q_{\mathrm{o}}(H)=C_{\mathrm{d}} A_{\mathrm{S}} \sqrt{2 g H_{\mathrm{e}}},
$$

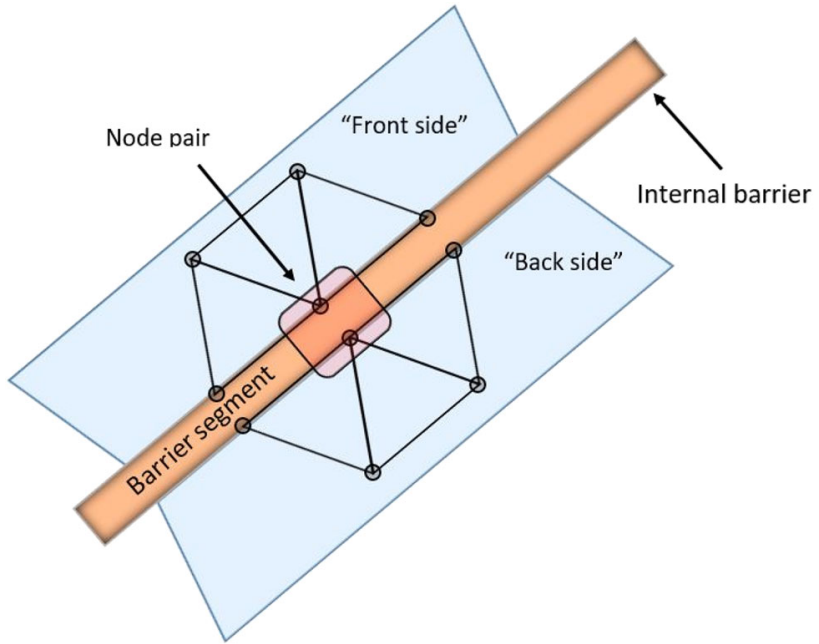

Fig. 5 Top view of internal (barrage) barrier and triangular element representation (from: Ma et al. 2019)

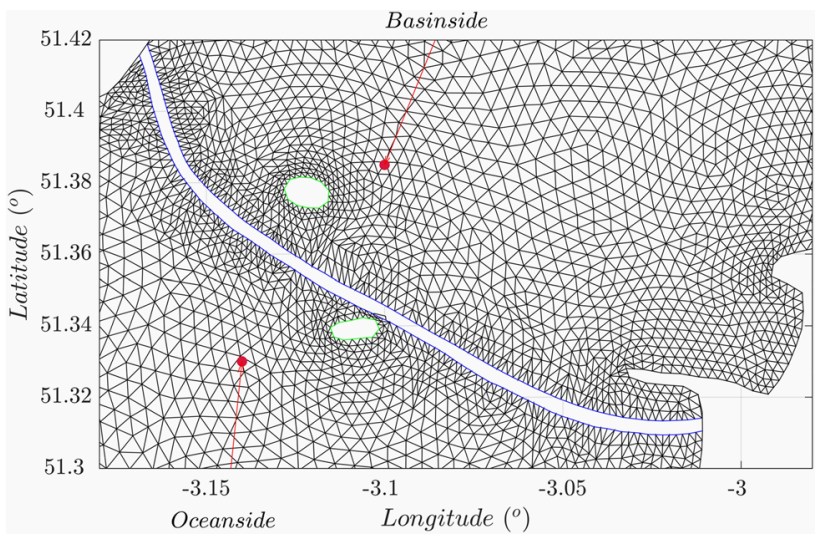

Fig. 6 Model computational details of the barrage layout for Severn Barrage, the blue lines indicate the barrage boundary and as shown, the region at the left-hand side is defined as basin side and the right as ocean side

where $Q_{\mathrm{o}}$ is the flow, $H_{\mathrm{e}}$ the head difference, $C_{\mathrm{d}}$ the discharge coefficient, $A_{\mathrm{S}}$ the sluice area and $g$ the gravity constant.

The focus of this project is the large-scale proposal for the Severn Barrage [(based on the original STPG scheme for the Cardiff-Weston Barrage (B3)] within the Severn Estuary (Fig. 6). The barrage has $216 \times 40 \mathrm{MW}, 9 \mathrm{~m}$ diameter bulb turbine generators, 166 sluice gates with total $35,000 \mathrm{~m}^{2}$ sluicing area, ship locks and other structures. The scheme is tested here under the two-way generation regime as suggested by Xia et al. (2010) and follows the configuration of the barrage design shown in Table 2. The detailed layout of the turbines and sluices is based on STPG (1989) (Fig. 7).

Under extreme storm conditions, it may be difficult to operate the barrage in the ideal manner we have assumed here. Hydraulic structures do not always maintain their performance during severe events. In this paper, we have assumed that such changes in behaviour can be ignored 
Table 2 Specifications of the Severn Barrage considered

\begin{tabular}{ll}
\hline Severn Barrage design & \\
\hline Operation scheme & Two way \\
No of turbines & 216 \\
Turbine capacity (MW) & 40 \\
Turbine diameter (m) & 9.0 \\
No. of sluice & 166 \\
Sluice area $\left(\mathrm{m}^{2}\right)$ & 35,000 \\
Barrage length $(\mathrm{km})$ & 16.1 \\
\hline
\end{tabular}

although we acknowledge these could be very important in practice.

\section{Results}

\subsection{Impact of barrage on tidal hydrodynamics}

Before we consider its impact on storm surges, it is important to understand the impact of the Severn Barrage on the tidal hydrodynamics. The tide is the key contributor to water levels and, therefore, something on which coastal flooding depends. The Severn Barrage is a relatively large project compared with other hydrodynamic options in the Bristol Channel, such as the Swansea Lagoon, and might be expected to have some
Table 3 Barrage operational scenarios with different starting heads and finishing heads

\begin{tabular}{lll}
\hline Case & Starting head $(\mathrm{m})$ & Finishing head $(\mathrm{m})$ \\
\hline A & 1.5 & 0.7 \\
B & 3.0 & 1.0 \\
C & 4.0 & 2.0 \\
D & $\infty$ & 0 \\
\hline
\end{tabular}

impacts on the tidal hydrodynamics. The tidal hydrodynamics of the Bristol Channel are a resonant system (Fong and Heaps 1978; Gao and Adcock 2017), and such systems can be sensitive to small changes. However, previous studies by Roger Falconer and coworkers (e.g. Bray et al. 2016) suggest that the impact on water levels outside the barrage is surprisingly small and localised.

In assessing the change to the naturally occurring hydrodynamics, we also need to consider different operational strategies. Becker et al. (2017) found that using a low starting head had a significantly smaller impact on the tide, hence minimising the environmental impact. In the present study, we consider a number of different operational scenarios set out in Table 3 [see standard works such as Prandle (1984) for discussion of starting and finishing head].

The final case, 'D', is essentially a closed barrage which we include as a limiting case. We analyse 28 days of simula-
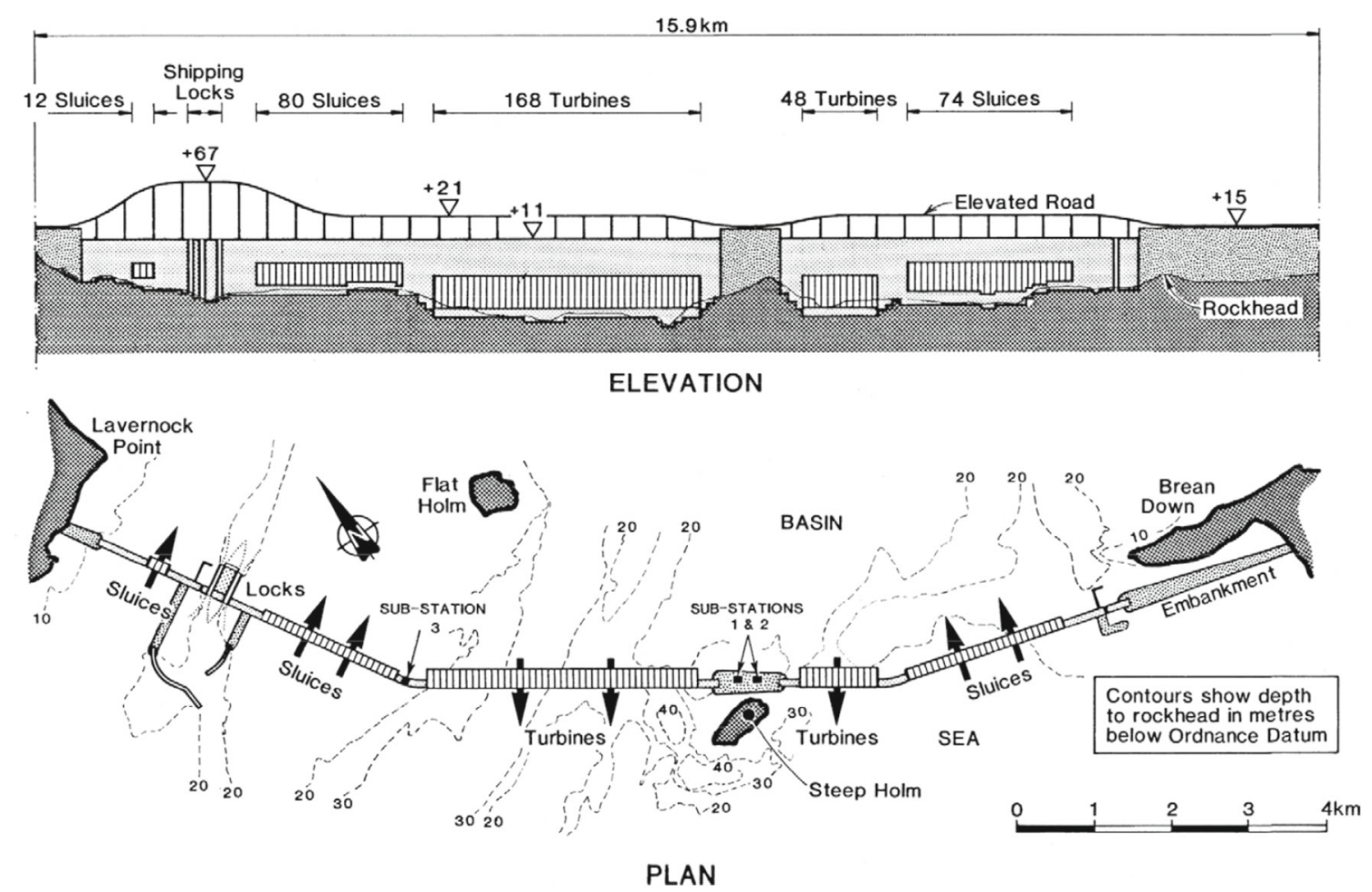

Fig. 7 Schematic of the Severn Barrage layout (based on STPG 1989) 
Table $4 \quad M_{2}$ amplitude at selected measurement stations: Barry $\left(51.21^{\circ} \mathrm{N} 3.22^{\circ} \mathrm{W}\right)$ and Hinkley Point $\left(51.22^{\circ} \mathrm{N} 3.13^{\circ} \mathrm{W}\right)$, for different operation scenarios

\begin{tabular}{lll}
\hline Case & Barry $(\mathrm{m})$ & Hinkley point $(\mathrm{m})$ \\
\hline No barrage & 3.91 & 3.97 \\
A & 3.44 & 3.47 \\
B & 3.37 & 3.39 \\
C & 3.32 & 3.33 \\
D & 3.50 & 3.53 \\
\hline
\end{tabular}
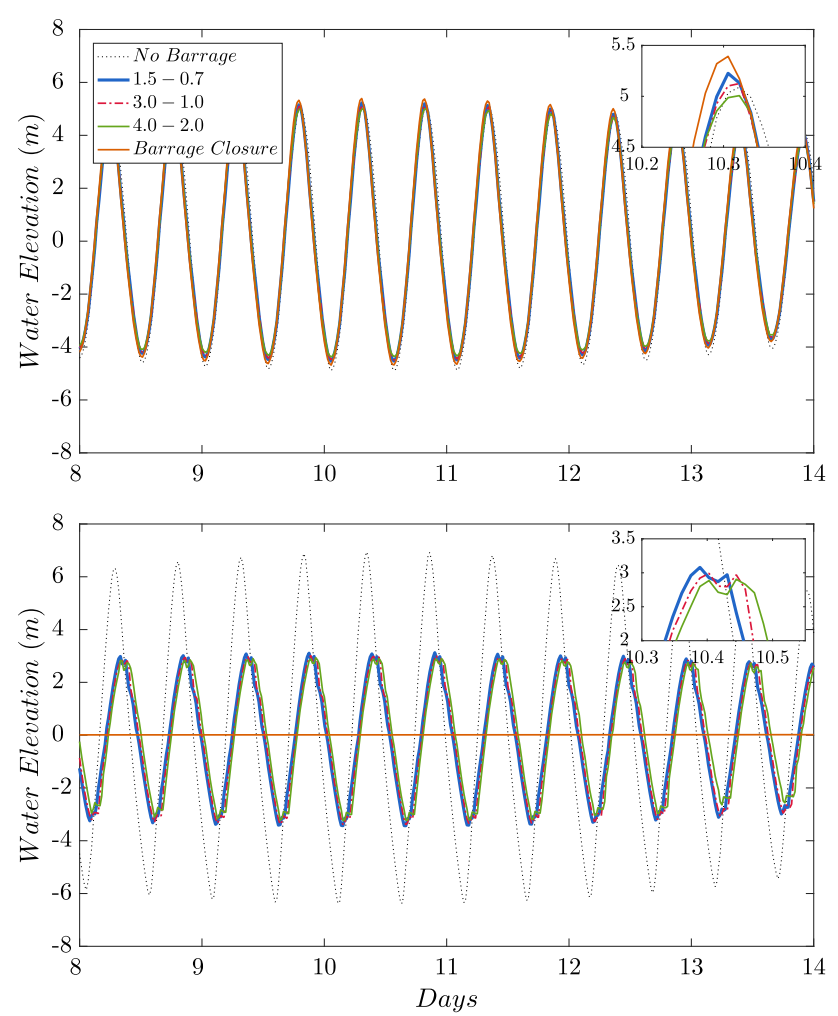

Fig. 8 Impact of different operational heads on the water elevations without meteorological forcing: (top) in the ocean side $\left(51.36^{\circ} \mathrm{N}\right.$ $\left.3.67^{\circ} \mathrm{W}\right)$; (bottom) in the basin side $\left(51.48^{\circ} \mathrm{N} 2.90^{\circ} \mathrm{W}\right)$

tion following a 4-day spin-up. We consider the water levels at the basin- and ocean side, the precise locations of which can be seen in Fig. 6.

The results generally show limited impact on the tides west of the Severn Barrage and significant reduction of tidal range in the basin (east of the barrage) for all of the scenarios considered. Table 4 presents the amplitude of the main tidal constituent on the seaward side of the barrage. Figure 8 shows a comparison between the model predicted water elevation for the natural case (no barrage) and for different barrage operation scenarios. All cases lead to a reduction in the tidal amplitude (and thus peak water level) outside the barrage probably due to the effective shortening (and damping) of the channel moving it further from resonance.
Table 5 Barrage operational strategies during the storm surge event

\begin{tabular}{lllll}
\hline Case & $\begin{array}{l}\text { Normal } \\
\text { operation } \\
\text { (days) }\end{array}$ & $\begin{array}{l}\text { Closure } \\
\text { period } \\
\text { (days) }\end{array}$ & $\begin{array}{l}\text { Opening } \\
\text { period } \\
\text { (days) }\end{array}$ & Details \\
\hline E & $0-8.1$ & $8.1-10.2$ & $10.2-14$ & $\begin{array}{c}\text { Fully-area } \\
\text { opening of } \\
\text { turbine and } \\
\text { sluice gates }\end{array}$ \\
F & $0-8.1$ & $8.1-10.2$ & $10.2-14$ & $\begin{array}{c}\text { Half-area } \\
\text { opening of } \\
\text { turbine and } \\
\text { sluice gates }\end{array}$ \\
\hline
\end{tabular}
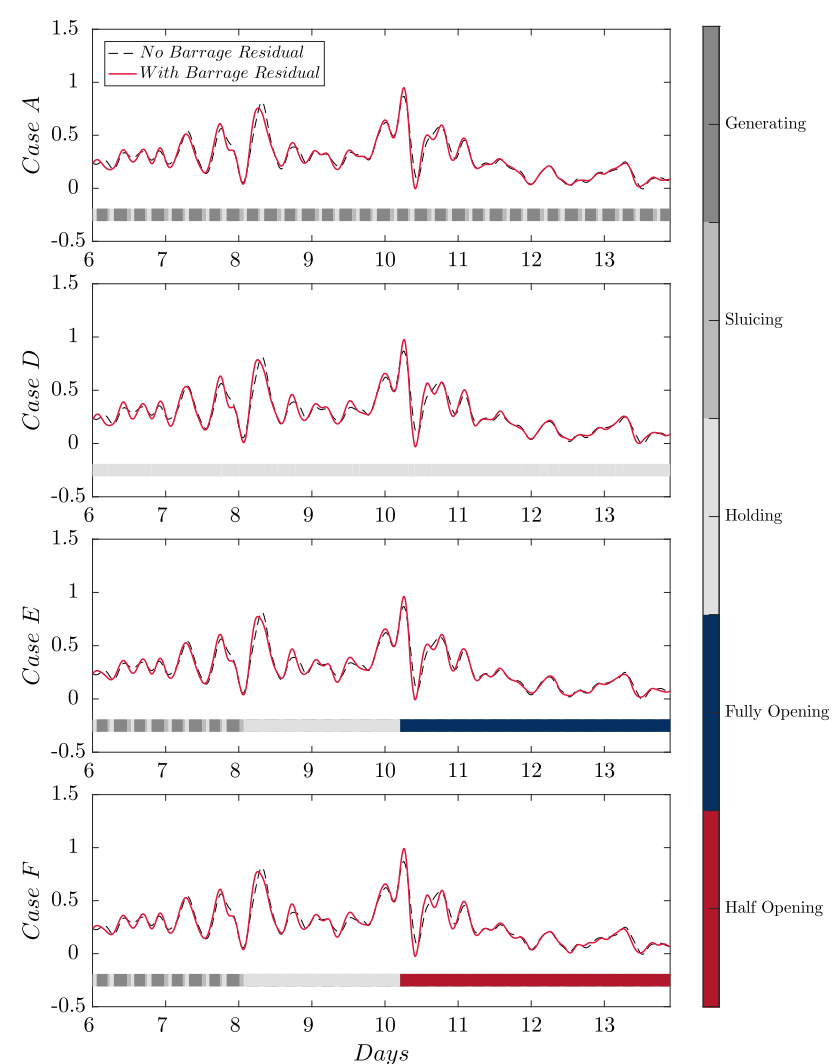

Fig.9 Residual level results in the ocean-side region $\left(51.36^{\circ} \mathrm{N} 3.67^{\circ} \mathrm{W}\right)$ of the four barrage operation strategies during storm surge: a barrage normal operation (first); b barrage complete closure (second); $\mathbf{c}$ barrage operation Case 'E' (third); d barrage operation Case 'F' (fourth)

The barrage implementation would have a significant influence on the enclosed basin region. The maximum water elevation is predicted to decrease by approximately $4 \mathrm{~m}$ (the mean level for ' $A$ ', ' $B$ ' and ' $C$ ' case) for a spring tide. The shifted phase of the peak should be related to the barrage operation stages. The barrage effects on lowest water levels are noticeable as well in the basin. The predicted level is $-6.36 \mathrm{~m}$ without the barrage and these values come around $-3.18 \mathrm{~m}$ for all the head cases. We do not carry out standard harmonic analysis within the basin as the water level has 


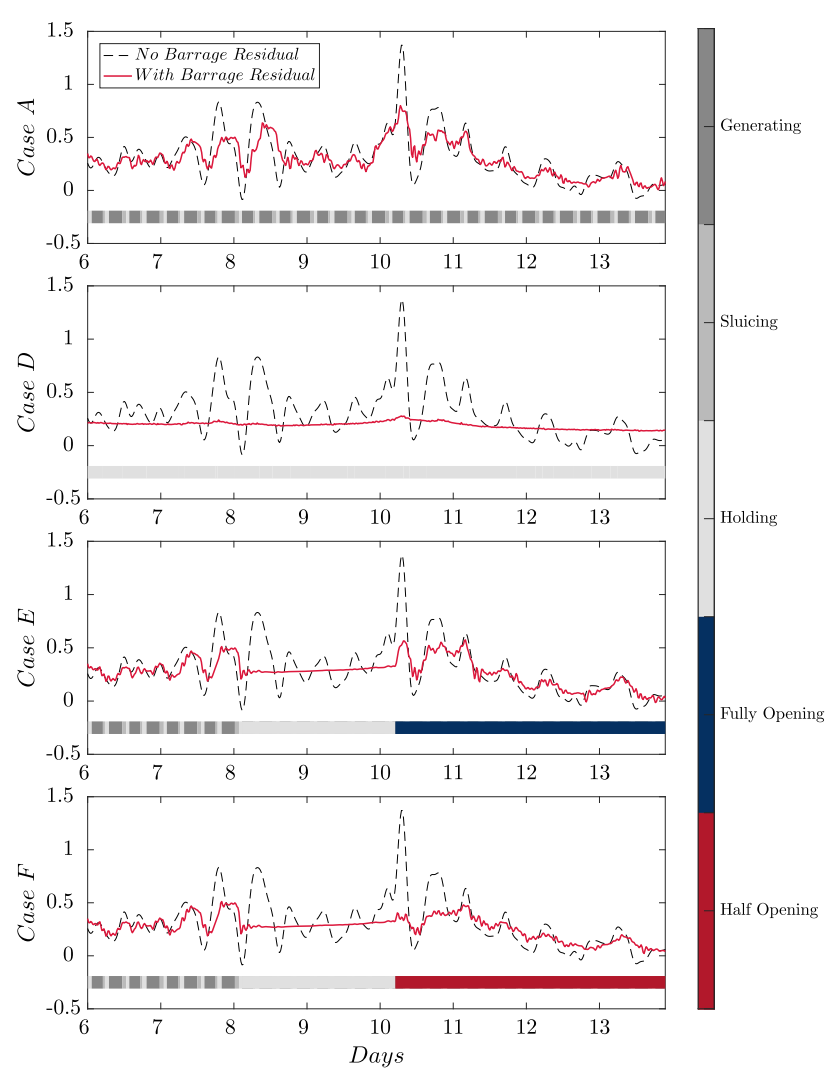

Fig. 10 Residual level results in the basin-side region $\left(51.48^{\circ} \mathrm{N}\right.$ $2.90^{\circ} \mathrm{W}$ ) of the four barrage operation strategies during storm surge: a barrage normal operation (first); $\mathbf{b}$ barrage complete closure (second); $\mathbf{c}$ barrage operation Case 'E' (third); $\mathbf{d}$ barrage operation Case ' $\mathrm{F}$ ' (fourth)

significant higher harmonics meaning these become a poor descriptor of the change in water level.

\subsection{Impact of barrage on storm surge hydrodynamics}

We now examine how the synthetic storm surge event is modified by the presence of the barrage (modified 2000 event applied). In this section, we try to understand the change due to the barrage on the 'residual' (i.e. the difference between the water level just from tides and the water level with tides and meteorological forcing). We consider a number of scenarios

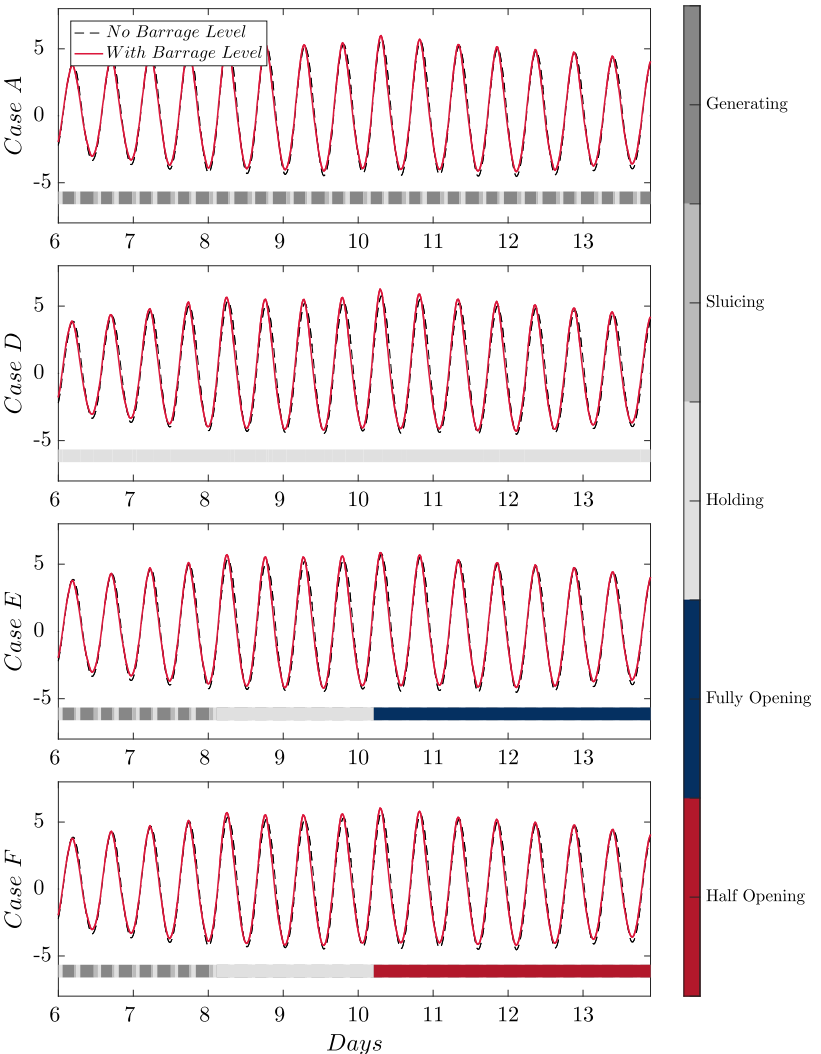

Fig. 11 Water level results in the ocean-side region $\left(51.36^{\circ} \mathrm{N} 3.67^{\circ} \mathrm{W}\right)$ of the four barrage operation strategies during storm surge: a barrage normal operation (first); $\mathbf{b}$ barrage complete closure (second); $\mathbf{c}$ barrage operation Case E (third); d barrage operation Case F (fourth)

(see Table 5) to see how these influence the storm surge. The first scenarios we consider are simply keeping the barrage operating as normal (Case 'A') or having a completely closed barrage (Case 'D'). Further, we consider scenarios where at low tide, and prior to the storm surge event, we close off the barrage to create a low water level within the basin. This void could, potentially, be filled with the excess water from the storm surge mitigating flooding. We consider two cases: where once the surge occurs we completely open the sluices (Case 'E') or just partially open the sluices (Case 'F').

Figures 9 and 10 present the residual on the ocean side and basin side of the barrage for Cases 'D', 'E' and 'F'. The different peak values are summarised in Table 6 .

Table 6 Comparison of peak results of different strategies for residual level in the ocean $\left(51.36^{\circ} \mathrm{N} 3.67^{\circ} \mathrm{W}\right)$ and basin $\left(51.48^{\circ} \mathrm{N} 2.90^{\circ} \mathrm{W}\right)$ region based on the original no-barrage results

\begin{tabular}{|c|c|c|c|c|c|c|c|c|}
\hline \multirow{2}{*}{$\begin{array}{l}\text { Case } \\
\text { Parameter }\end{array}$} & \multicolumn{2}{|l|}{ Case A } & \multicolumn{2}{|l|}{ Case D } & \multicolumn{2}{|l|}{$\underline{\text { Case E }}$} & \multicolumn{2}{|l|}{$\underline{\text { Case F }}$} \\
\hline & Ocean & Basin & Ocean & Basin & Ocean & Basin & Ocean & Basin \\
\hline Observation value $(\mathrm{m})$ & 0.95 & 0.80 & 0.98 & 0.28 & 0.96 & 0.57 & 0.99 & 0.39 \\
\hline Peak time change (h) & 0.24 & -0.24 & 0.24 & 0.00 & 0.24 & 0.72 & 0.24 & 1.44 \\
\hline Magnitude change (m) & 0.08 & -0.57 & 0.11 & -1.09 & 0.09 & -0.81 & 0.12 & -0.98 \\
\hline
\end{tabular}




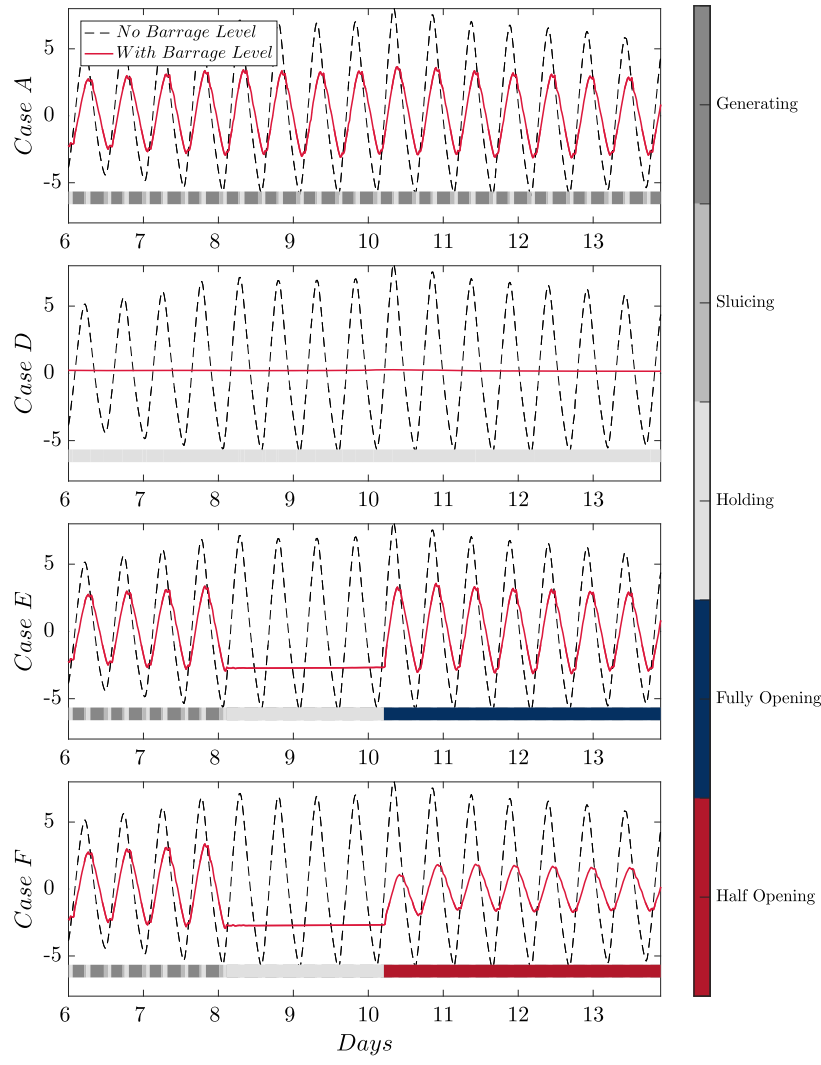

Fig. 12 Water level results in the basin-side region $\left(51.48^{\circ} \mathrm{N} 2.90^{\circ} \mathrm{W}\right)$ of the four barrage operation strategies during storm surge: a barrage normal operation (first); $\mathbf{b}$ barrage complete closure (second); $\mathbf{c}$ barrage operation Case E (third); $\mathbf{d}$ barrage operation Case F (fourth)

In all cases, the presence of the Severn Barrage increases the size of the residual on the ocean side of the basin. This increase is between 9 and $15 \%$. There is a small delay in the timing of the peak residual but in all cases this is less than $15 \mathrm{~min}$ and so unlikely to make a practical difference. We find the peak in the residual is only weakly dependent on the strategy used and, in fact, greatest residual is for Case ' $\mathrm{F}$ '.

On the basin side of the barrage, the peak residual is reduced considerably due to the presence of the barrage. The reduction is strongly dependent on the strategy used. The greatest reduction is found in Case ' $\mathrm{D}$ ' (simply closing the barrage) where the change in water level is simply due to local meteorological forcing of the water inside the basin. However, the peak residual can be reduced nearly as much by operating strategy ' $F$ '. In strategy ' $F$ ', the time of the peak in the residual is also delayed.

\subsection{Impact of barrage on extreme water level during surge event}

We now turn to the maximum water level observed during our simulations. This is obviously the variable of most interest in terms of coastal flooding. It will be a non-linear function of both the changes in tidal hydrodynamics and storm surge dynamics. We again use representative points on either side of the barrage for our analysis. Figures 11 and 12 compare time histories of the water levels on either side of the barrage for the different strategies considered above against the undisturbed water level. The peak levels are summarised in Table 7.

On the ocean side of the barrage, the peak water level is slightly higher than if there were no barrage present. The difference is relatively small as there are two competing effects- the reduction in the tidal amplitude due to the barrage and the increase in storm surge elevation due to the barrage. The strategy chosen has an influence on these levels. The most favourable is Case ' $\mathrm{E}$ ' where the barrage is closed at low water prior to the surge event and then opened to absorb the excess water during the storm surge.

Within the basin, there is the expected reduction in the peak water level given that both tidal amplitudes and storm surges are reduced by the presence of the barrage. This reduction is very significant showing that the barrage would provide considerable protection against flooding. The amount of the reduction is dependent on the operating strategy used-operating the barrage following Case ' $F$ ' gives almost as much reduction in water level as completely isolating the water inside the barrage (Case 'D'). The timing of the peak of the surge can also vary by over an hour depending on the strategy used.

\section{Discussion}

In this paper, we have run a hydrodynamic model to gain an insight into how the Severn Barrage would alter extreme water levels in the region. Our analysis is restricted to a single storm surge event but one which is based on real meteorological and tidal conditions. We have assumed that the equations governing the behaviour of the barrage will remain unchanged during a severe weather event. It is clear that the barrage can provide significant protection from coastal flooding for the cities of Bristol and Cardiff and other locations to the east of the barrage. However, there would be an increase in the extreme wave level that would be expected to the west of the barrage which might impact on flooding in areas such as the Somerset levels. To do an exact calculation of the extra risk is challenging but qualitatively the increase in water level expected is of the same order of magnitude as that expected from sea level rise $(10 \mathrm{~s}$ of $\mathrm{cm})$. Careful operation of the barrage can make a small, but perhaps significant, difference to the extreme water level during a storm surge event. Exactly which strategy is optimal would depend on the weight placed on changes to water level up- and downstream, as well as the impact of interrupting power generation during a spring tide. 
Table 7 Comparison of peak results of different strategies for water elevation in the ocean $\left(51.36^{\circ} \mathrm{N} 3.67^{\circ} \mathrm{W}\right)$ and basin $\left(51.48^{\circ} \mathrm{N} 2.90^{\circ} \mathrm{W}\right)$ region based on the original no-barrage results

\begin{tabular}{|c|c|c|c|c|c|c|c|c|}
\hline \multirow{2}{*}{$\begin{array}{l}\text { Case } \\
\text { Parameter }\end{array}$} & \multicolumn{2}{|l|}{ Case A } & \multicolumn{2}{|l|}{$\underline{\text { Case D }}$} & \multicolumn{2}{|l|}{$\underline{\text { Case E }}$} & \multicolumn{2}{|l|}{ Case F } \\
\hline & Ocean & Basin & Ocean & Basin & Ocean & Basin & Ocean & Basin \\
\hline Observation value (m) & 5.99 & 3.66 & 6.28 & 0.29 & 5.86 & 3.30 & 6.05 & 1.08 \\
\hline Peak time change $(\mathrm{h})$ & 0.00 & 1.44 & -0.48 & -0.24 & -0.48 & 1.44 & -0.48 & 2.16 \\
\hline Magnitude change (m) & 0.23 & -4.38 & 0.52 & -7.75 & 0.10 & -4.73 & 0.29 & -6.95 \\
\hline
\end{tabular}

The present paper only considers the possible impact of flooding from coastal storm surges. As with other storm surge barrages (Thames Barrier and Maeslant Barrier), these could also be used to reduce the impact on river flooding in the Severn and other rivers flowing into the basin to the east of any barrage. This would require the barrage to be operated appropriately. This operation might be sub-optimal in terms of flooding from storm surge, if river and storm surge flooding were to coincide.

The present paper only considers one aspect of the impact a Severn Barrage would have on the environment. The decision as to whether to build the barrage is a complex one and will depend on many factors: political, economic and environmental. In this paper, we have only looked at one factor: coastal flooding. Our analysis in this paper suggests that one benefit of such a scheme would be to lower the risk of severe coastal flooding in the major population centres on the Severn Estuary whilst having a small negative impact on coastal flooding to the west of the proposed barrier. As such, in our opinion, there would be a net benefit in terms of flood risk from building the barrage.

Acknowledgements QM was supported by the Chinese Scholarship Council and TMM acknowledges the Brazilian funding agency CAPES for fellowship support towards this work. We are grateful to Stephen Grey (HR Wallingford) and Jean Bidlot (ECMWF) for help of the meteorological data.

Open Access This article is distributed under the terms of the Creative Commons Attribution 4.0 International License (http://creativecomm ons.org/licenses/by/4.0/), which permits unrestricted use, distribution, and reproduction in any medium, provided you give appropriate credit to the original author(s) and the source, provide a link to the Creative Commons license, and indicate if changes were made.

\section{References}

Adcock TAA, Draper S (2014) On the tidal stream resource of two headland sites in the English Channel: Portland Bill and Isle of Wight. In: Proceedings of the International Conference on Offshore Mechanics and Arctic Engineering 9A:1-10

Aggidis GA, Feather O (2012) Tidal range turbines and generation on the Solway Firth. Renew Energy 43:9-17

Ahmadian R, Falconer R, Lin B (2010) Hydro environmental modelling of proposed Severn barrage, UK. Proc Inst Civil Eng Energy 163(3):107-117
Baker C (1991) Tidal power. Institution of Electrical Engineers, London Becker A, Plater A, Wolf J (2017) The energy river: realising energy potential from the river Mersey. Tech. rep, Liverpool City Council, Liverpool

Bondi H (1981) Tidal power from the Severn Estuary: report to the Secretary of State for Energy. Tech. rep, Department of Energy, Severn Barrage Committee, London

Bray S, Ahmadian R, Falconer RA (2016) Impact of representation of hydraulic structures in modelling a Severn barrage. Comput Geosci 89:96-106

Bryant K, Akbar M (2016) An exploration of wind stress calculation techniques in hurricane storm surge modeling. J Mar Sci Eng 4(3):58

Dawson C, Kubatko EJ, Westerink JJ, Trahan C, Mirabito C, Michoski C, Panda N (2011) Discontinuous Galerkin methods for modeling Hurricane storm surge. Adv Water Resour 34(9):1165-1176

DECC (2008) Analysis of options for tidal power development in the Severn Estuary. Interim Options Analysis Report. Department of Energy and Climate Change, Bristol

Dee DP, Uppala SM, Simmons AJ, Berrisford P, Poli P, Kobayashi S, Andrae U, Balmaseda MA, Balsamo G, Bauer DP, Bechtold $P$ (2011) The ERA-interim reanalysis: configuration and performance of the data assimilation system. Q J R Meteorol Soc 137(656):553-597

Draper S (2013) On the optimum place to locate a tidal fence in the Severn Estuary. In: Proceedings of the 2nd Oxford Tidal Energy Workshop, vol 1. University of Oxford, England, pp 23-24

Falconer RA, Xia J, Lin B, Ahmadian R (2009) The Severn Barrage and other tidal energy options: hydrodynamic and power output modeling. Sci China Ser E Technol Sci 52(11):3413-3424

Fong SW, Heaps NS (1978) Note on quarter wave tidal resonance in the Bristol Channel. Institute of Oceanographic Sciences

Gao C (2017) Analysis of storm surge and tidal resonance in the Bristol Channel. MSc Thesis, University of Oxford

Gao C, Adcock TAA (2017) On the tidal resonance of the Bristol Channel. Int J Offshore Polar Eng 27(2):177-183

Hafren Power (2013) Severn Barrage Business Case. Hafren Power, London, UK

Hendry C (2016) The role of tidal lagoons. Tech. rep, UK Government

Horsburgh K, Horritt M (2006) The Bristol Channel floods of 1607reconstruction and analysis. Weather 61(10):272-277

Kubatko EJ, Westerink JJ, Dawson C (2006) hp discontinuous Galerkin methods for advection dominated problems in shallow water flow. Comput Methods Appl Mech Eng 196(1-3):437-451

Lyddon C, Plater AJ, Brown JM, Prime T, Wolf J (2015) The impact of tidal lagoons on future flood risk on the North Wirral and Conwy coastline. UK. National Oceanography Centre, Southampton, UK

Ma Q, Moreira TM, Adcock TAA (2019) Impact of the Swansea Bay lagoon on storm surges in the Bristol Channel. In: Proceedings of the 38th international conference on ocean, offshore and arctic engineering, Glasgow, UK

Met Éireann (2018) Met Éireann re-analysis climate re-analysis. https:// www.met.ie/climate/available-data/mera. Accessed 23 Sep 2018 
Neill SP, Angeloudis A, Robins PE, Walkington I, Ward SL, Masters I, Lewis MJ, Piano M, Avdis A, Piggott MD, Aggidis G, Evans P, Adcock TAA, Židonis A, Ahmadian R, Falconer R (2018) Tidal range energy resource and optimization-past perspectives and future challenges. Renew Energy 127:763-778

Petley S, Aggidis G (2016) Swansea Bay tidal lagoon annual energy estimation. Ocean Eng 111:348-357

Prandle D (1984) Simple theory for designing tidal power schemes. Adv Water Resour 7(1):21-27

Proctor R, Flather RA (1989) Storm surge prediction in the Bristol Channel-the floods of 13 December 1981. Cont Shelf Res 9(10):889-918

Pugh DT (1996) Tides. Surges and mean sea-level, Wiley, Swindon

Rainey R (2009) The optimum position for a tidal power barrage in the Severn Estuary. J Fluid Mech 636:497-507

RMS (2007) 1607 Bristol Channel Floods: 400-year retrospective. Risk management Solutions Report

Schnabl AM, Moreira TM, Wood D, Kubatko EJ, Houlsby GT, McAdam RA, Adcock TAA (2019) Implementation of tidal stream turbines and tidal barrage structures in DG-SWEM. In: Proceedings of the 38th international conference on ocean, offshore and arctic engineering, Glasgow, UK

Serhadlıoğlu S (2014) Tidal stream resource assessment of the Anglesey Skerries and the Bristol Channel. DPhil Thesis, University of Oxford
Serhadlığlu S, Adcock TAA, Houlsby GT, Draper S, Borthwick AGL (2013) Tidal stream energy resource assessment of the Anglesey Skerries. Int J Mar Energy 3:e98-e111

STPG (1989) The Severn Barrage project: general report. Severn Tidal Power Group, Department of Energy (DE), London, UK

Westerink JJ, Luettich RA, Militello A (2001) Leaky internal-barrier normal-flow boundaries in the ADCIRC coastal hydrodynamics code. US Army Corps of Engineers

Westerink JJ, Luettich RA, Feyen JC, Atkinson JH, Dawson C, Roberts HJ, Powell MD, Dunion JP, Kubatko EJ, Pourtaheri H (2008) A basin- to channel-scale unstructured grid hurricane storm surge model applied to Southern Louisiana. Mon Weather Rev 136(3):833-864

Wu J (1969) Wind stress and surface roughness at air-sea interface. J Geophys Res 74(2):444-455

Xia J, Falconer RA, Lin B (2010) Impact of different operating modes for a Severn Barrage on the tidal power and flood inundation in the Severn Estuary. UK. Appl Energy 87(7):2374-2391

Publisher's Note Springer Nature remains neutral with regard to jurisdictional claims in published maps and institutional affiliations. 